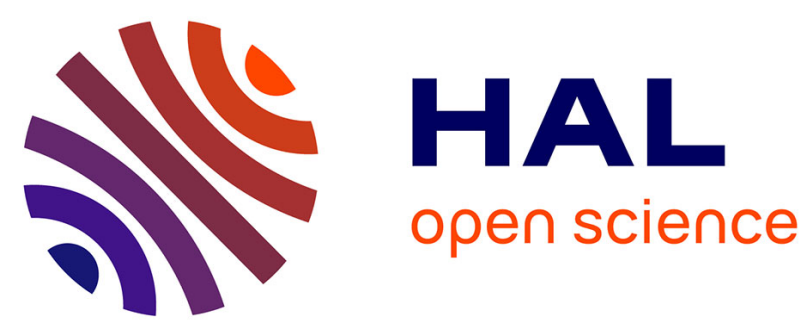

\title{
Prediction of Process Time for Early Production Planning Purposes
}

Mads Bejlegaard, Thomas Ditlev Brunoe, Kjeld Nielsen

\section{To cite this version:}

Mads Bejlegaard, Thomas Ditlev Brunoe, Kjeld Nielsen. Prediction of Process Time for Early Production Planning Purposes. IFIP International Conference on Advances in Production Management Systems (APMS), Sep 2015, Tokyo, Japan. pp.406-413, 10.1007/978-3-319-22756-6_50 . hal-01417520

\author{
HAL Id: hal-01417520 \\ https://hal.science/hal-01417520
}

Submitted on 15 Dec 2016

HAL is a multi-disciplinary open access archive for the deposit and dissemination of scientific research documents, whether they are published or not. The documents may come from teaching and research institutions in France or abroad, or from public or private research centers.
L'archive ouverte pluridisciplinaire HAL, est destinée au dépôt et à la diffusion de documents scientifiques de niveau recherche, publiés ou non, émanant des établissements d'enseignement et de recherche français ou étrangers, des laboratoires publics ou privés. 


\title{
Prediction of process time for early production planning purposes
}

\author{
Mads Bejlegaard, Thomas Ditlev Brunoe, Kjeld Nielsen \\ Department of Mechanical and Manufacturing Engineering, Aalborg University \\ bejlegaardem-tech.aau.dk
}

\begin{abstract}
The production ramp-up process is critical to stay competitive and to capture market share but there are some common problems encountered during ramp-up. Among others one problem is related to the maturity of the production processes, including unforeseen bottlenecks. This paper contributes to the production planning part of the ramp-up process by showing how to predict the process time for new parts that is to be introduced in an existing manufacturing environment. A statistical model based on historical product-data is applied and the potential advantages of the model are outlined.
\end{abstract}

Keywords: Regression, ramp-up, production planning, Reconfigurable Manufacturing Systems

\section{$1 \quad$ Introduction}

In the context of changing market conditions due to globalization, companies experience fluctuations in product demand besides the need of introducing new innovative products more often [6]. Hence, the ramp-up process is critical to stay competitive and to increase market share. The production ramp-up is introduced in the new product development (NPD) but little literature studies in detail the ramp-up issue [11]. One common characteristic of the ramp-up phase is the lack of planning reliability [8]. In a comprehensive study on production ramp-up, common problems encountered during ramp-up are classified and includes problems which are related to the maturity of the production processes [11]. This includes slow set-ups, unforeseen bottlenecks, and manufacturability of the products (i.e. product design-process fit) [11]. The ability to accurately predict the process time for new parts that are to be introduced in an existing or new manufacturing environment can prevent or reduce the above mentioned problems by increasing the accuracy of the production planning (i.e. design of the manufacturing system).

The Reconfigurable Manufacturing System (RMS) is a new manufacturing system paradigm which is partly designed to meet these ramp-up issues. Thus RMS works towards the ability to rapidly adapt to new market conditions (i.e. change to the exact capacity and functionality needed when needed) [7]. However, new parts or a new product family introduced in existing manufacturing environments will often be incorporated in a balanced flow, which is why accurate prediction of process times to

adfa, p. 1, 2011

(C) Springer-Verlag Berlin Heidelberg 2011 
predict future requirements to the manufacturing system in an early stage is relevant. Ideally the RMS provides the ability to change functionality of existing systems and machines to suit new production requirements and scale the capacity by adding, removing or rearranging manufacturing resources and system components [7]. However, a prediction of the process time will still provide beneficial knowledge of the capacity needed when reconfiguring the system.

Some manufacturing equipment can provide the information of the expected process time, e.g. a robot programmed for a certain cycle. However, this information will only be available after the programing, and thus prediction of the process time on an earlier stage is valuable in the context of rapid configuration on a system level (see Fig. 2), e.g. balancing a line. Furthermore, it is difficult to predict the process time on manual processes. However, it is easier to adjust the capacity on manual manufacturing processes due to the human flexibility; early information of the process time still has influence on the ramp-up in relation to the production planning.

This paper addresses the issue of late knowledge of the actual time it takes to produce new parts that are to be introduced in a new or existing manufacturing environment. Similar work has not been identified whereas many methods have been developed for cost estimation [2], [3], [10], and [12]. One of these determines a method for using historical data for cost estimation for quotation purposes using statistics [1]. Likewise, this paper presents a case study of applying a statistical model. In this case for time estimation sufficiently accurate for a more precise estimation of process times for the purpose of more accurate production planning during ramp-up. Thus, it is shown that it is possible to predict process times.

\section{Method}

An extract of historical, registered process time was made from the database of an ERP system in a large Danish manufacturer of industrial equipment, while the rest of the data used was manually gathered from a CAD system. The historical process time is the mean of registered process time related to a part from the last five quarters. The research is based on a part family and the related processes in a welding department as visualized in [14]. First of all, parts undergoing the same processes running through the welding department were divided into families. Second, a family was selected and the routing deduced, all in order to demarcate the analysis.

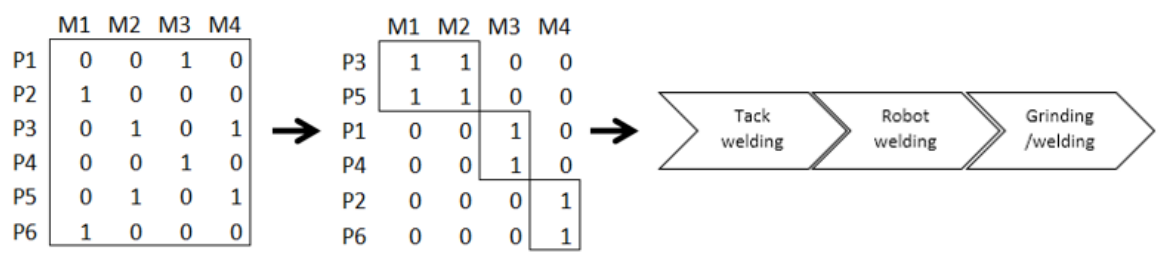

Fig. 1 Part family clustering for routing formation in order to demarcate the analysis, where M's are machines (i.e. cell level in Fig. 2) and P's are parts. 
The data consists of the parts in this particular part family, how many times they were produced, and the process time for each time they were produced in the sample period. The rest of the data (referred to as product-data) includes part weight, number of subcomponents, part dimensions (i.e. area and volume).

A linear regression analysis is applied to analyze the relations between the independent variables (i.e. product-data) and the dependent variables (i.e. historical, registered process time related to the product parts undergoing the processes in the chosen routing). As illustrated in Fig. 2, the regressions are made on various levels of the manufacturing system as described by [14] first on the segment level and successively traversing to lower levels until an acceptable level of accuracy is obtained. The analysis takes it starting point at the segment level as a relation between process time and product data is expected to show when the overall process technology gets common to all included parts, e.g. welding, machining etc. As a function of effect size (i.e. relation between variables) and the level of significance a sample size between 12 and 30 is required [5]. Hereby, you can argue that the validity of the analysis gets unreliable if the sample size gets under 12, when it is divided in underlying levels, even with a strong relation between variables.

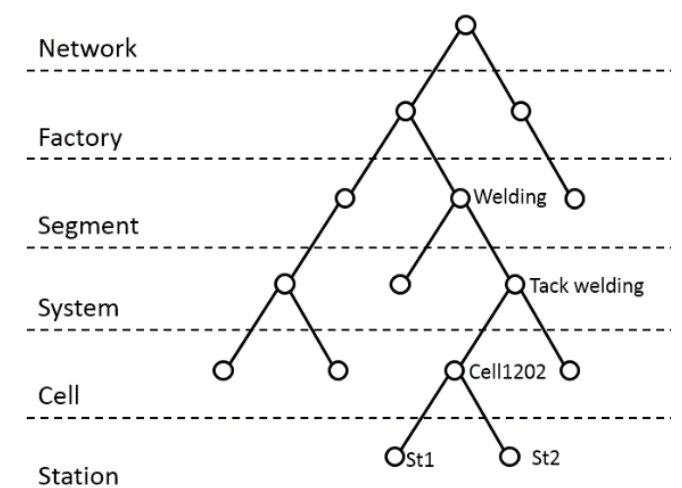

Fig. 2 Breakdown structure of the manufacturing system, inspired by [13], [14]

Some of the independent variables can appear insignificant or appear as noise to the result. One method to find the most precise combination of variables is to test all alternative combinations of the independent variables that can be considered. Although, only a maximum of seven independent variables are used it will imply testing 13,699 linear combinations. Instead $P$ is applied to determine whether independent variables should be excluded from the model. The $P$-value is the probability that the prediction will take on a value that is at least as extreme as the observed value when the null hypothesis $H_{0}$ is true [9]. Alternatively stepwise regression could be applied in cases of many variables which is a particular method for arriving at linear model and is applied when a reduced linear model is desired, as presented in [1]. The variables include part weight, number of subcomponents, part dimensions (i.e. area and volume), which was the available product information. The mandatory data is the time used on each part in each process. Depending on the sequence in which the re- 
gressions are made the process time from the first process in the routing of the part family (i.e. the dependent variable) can be applied as an independent variable for the next regression etc.

In order to determine the system level (see Fig. 2) on which, an acceptable prediction accuracy is obtained an evaluation criteria must be set. It is often seen that residual sum of squares $\left(\mathrm{R}^{2}\right.$ or modified $\left.\mathrm{R}^{2}\right)$, i.e. how well the observed data fits the model, is used. However as it is argued in [1], it may be difficult to translate this measure into a business term, why Mean Absolute Percentage Error (MAPE) can be used instead as an evaluation criteria to compare the predicted values the observed values.

\section{$3 \quad$ Results}

Fig. 3, Fig. 4, and Fig. 5 show the results for the analysis performed to determine the level accuracy in predicting the process time. Since the regression analysis was carried out on the manual tack welding cell as the first of the three cells in the particular routing, this only included four independent variables. Thus one variable can be added to the pool of independent variables for each step (i.e. move from one system area to the next based on the routing). However, the results on system level (including tack welding, robot welding and grinding/welding) did not obtain the desired level of accuracy.

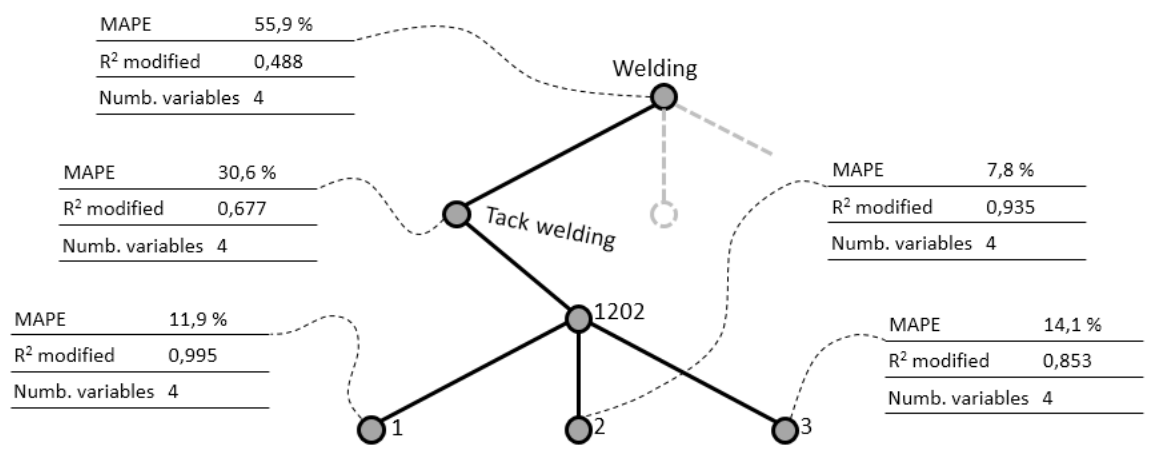

Fig. 3 Results related to tack welding and the identification of prediction accuracy at each of the included manufacturing system levels

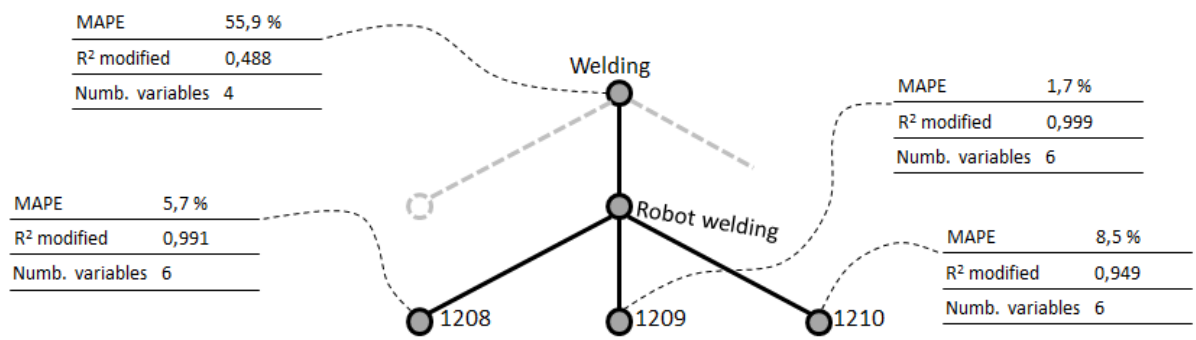

Fig. 4 Results related to robot welding and the identification of prediction accuracy at each of the included manufacturing system levels 


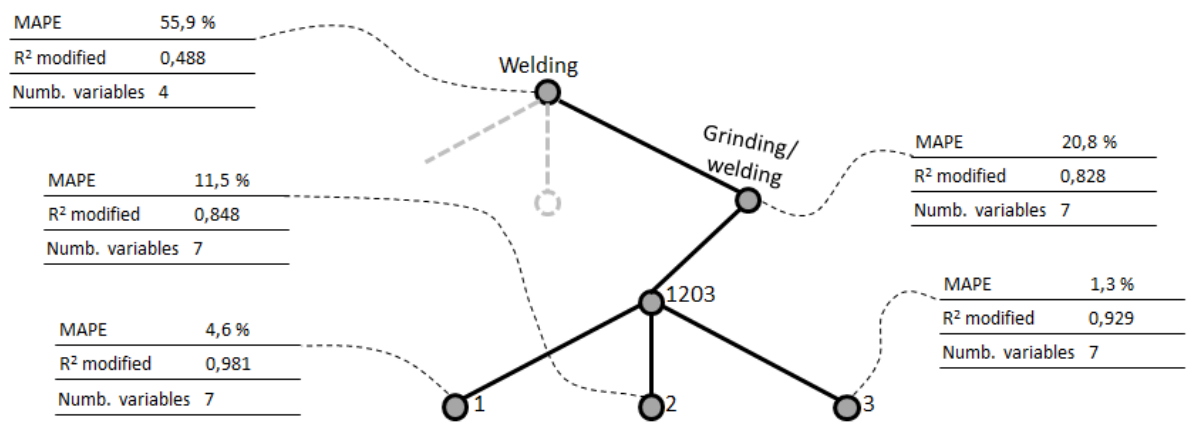

Fig. 5 Results related to grinding/welding and the identification of prediction accuracy at each of the included manufacturing system levels

For this reason these were broken down into cells or stations (if only one cell was represented) to obtain more accurate predictions.

MAPE is the measure of how much the predicted time values in average deviate from the observed time values using the regression model. $\mathrm{R}^{2}$ represents how well the regression model describes the variation in the observed data. The $\mathrm{R}^{2}$ indicates how well the data fits the model, and thus a higher $\mathrm{R}^{2}$ value indicates a better model, i.e. $\mathrm{R}^{2}$ equal to 1 indicates a perfect fit. As it is illustrated in Fig. 3, Fig. 4, and Fig. 5, fewer variables are related to a lower $\mathrm{R}^{2}$ value and a higher MAPE. This can explain why cell 1203 achieves better result than 1202 .

To further improve the result instead of dividing into stations on the lowest level (see Fig. 2) it was tried to group the parts on the basis of the independent variables, i.e. further grouping on the basis of either weight, number of subcomponents, part dimensions (i.e. area and volume). This did however not improve the output of the analysis.

Compared to the estimation method applied until now, this model is more accurate. The methods currently used in the case company for estimating process times has average deviations between predicted times and actual times of approximately $25 \%$ while the results presented gives an MAPE of $7.5 \%$.

\section{Discussion}

The chosen approach for grouping processes in the welding department was executed on the basis of the manufacturing system composition (i.e. structural system components). Instead, the grouping could have been based on classifications rather than the composition as illustrated in Fig. 6. The classification primarily supports the identification of components and the basic structure at the type level [4] i.e. each component at each system level has its one components and structure. 


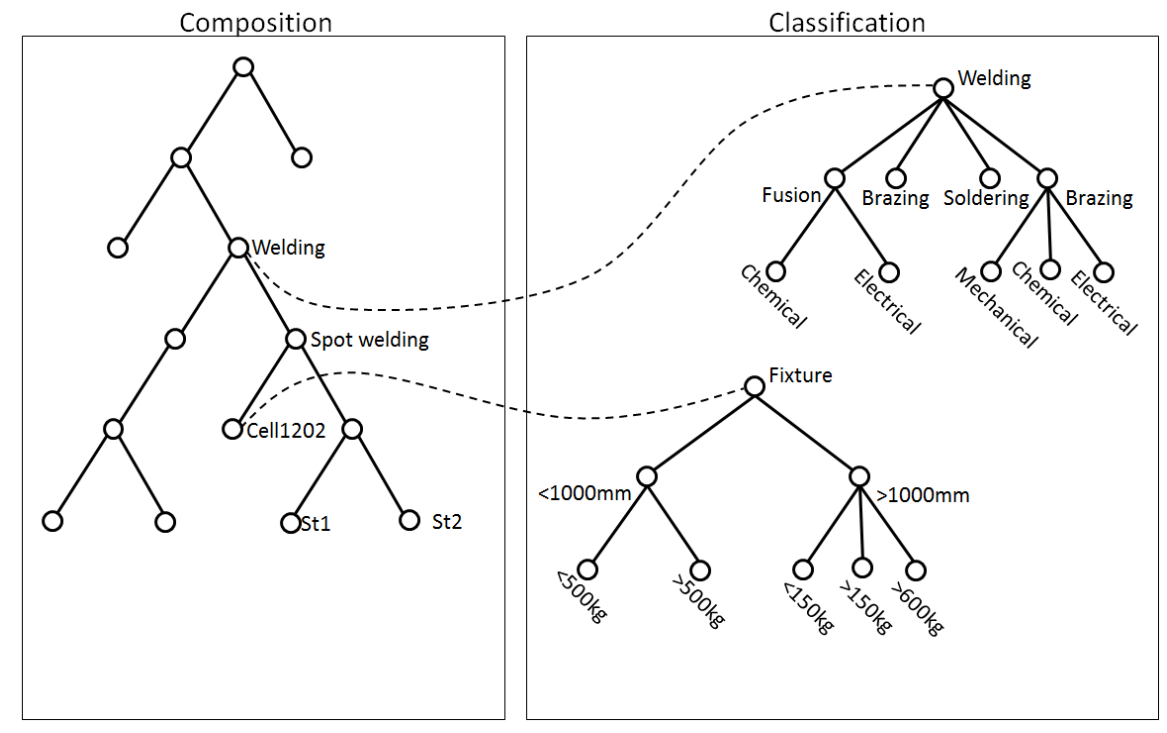

Fig. 6 Both composition and classification can be applied as two different approaches for structuring a process breakdown for the purpose of identifying commonalities in processes. Inspired by [4]

It is not unusual that one observation deviates $25 \%$ from the average of the observed time values in the sample period, even when potential outliers is sorted from the rest. The operators' time consumption at the included stations tends to have a higher degree of fluctuation for manual processes compared to semi-automated processes. This may be due to semi-automated processes' fixed procedures but in general the fluctuation may be caused by a lack of responsibility to the customer process and an insufficiently implemented process execution procedure. This can explain better prediction accuracy for the semi-automated process using the regression model. For this reason the accuracy of the result may be improved if the sequence of regression analyses switched to start on the basis of data from processes with fixed procedures and then use the dependent variable from this analysis as an independent variable in the next etc., instead of following the sequence of the routing.

Since the model uses historical data it is worth considering how to keep the data on which the predictions are made, updated. Most of manufacturing processes are underlying continues improvements and new parts are constantly introduced, and thus new data emerges. Furthermore, it would be reasonable to expect increasing learning curves following process changes, thus increased efficiency of employees could be expected. The updating frequency of the data then becomes an important issue. This issue is currently not addressed, but it will be crucial to update the data when changes occur to the process. Knowledge of the frequency of which updated procedures or process changes occurs could be used to infer an appropriate updating frequency. 


\section{Conclusion}

One common characteristic of the ramp-up phase is the lack of planning reliability, which is amplified by slow set-ups and unforeseen bottlenecks. An important part of preventing these issues is to make a more accurate planning on an early stage by improving the prediction of the actual time it takes to manufacture new parts that are to be introduced in a new or existing manufacturing environment.

This paper addresses to which extent it is possible to predict the time needed to produce parts in a manufacturing system for planning purposes. As a case for investigating the applicability of the method, a part of a manufacturing system performing welding is used as a case. The method starts by producing a model, which can predict time for a wide range of components, and successively divides the data set into more specific groups of components to increase accuracy of the predictions.

Furthermore, the system level, on which an acceptable precision in predicting the process time is obtained, is determined. The case company's estimation of expected process time for new parts shows an average deviation from the observed process time (i.e. MAPE) on $25.2 \%$ while the results presented give an average deviation of $7.5 \%$. Based on the level of deviation in the data related to each part the results are rather promising. The results further indicated a relation between the prediction accuracy and the level of automation, since the prediction of the process time on a semiautomated process had greater accuracy. It is likely that information of competence level could be included to increase the prediction accuracy on manual processes, e.g. include information on operators capabilities or if the work is performed by an apprentice. However, this would conflict with the broad use of the model unless operators with certain levels of competencies are permanently dedicated specific processes.

The model can be applied in many contexts, e.g. introducing a new part or new products in an existing or new manufacturing environment if the necessary historical data to predict the process time is available. This can potentially reduce the costs related to inaccurate production planning (i.e. reduce the cost of slow set-ups and unforeseen bottlenecks). In cases of high MAPE, the model can be used as an indicator that the process is not properly designed or that tools are not appropriate for the job, i.e. indirectly, the model can indicate that one process is not performing as well as the majority of the processes.

Using the model in relation to the composition structure gives a generic approach while using the classification approach is more likely to be individual. The composition structure follows the hierarchical structure that is easy to apply but classification structures could provide a higher prediction accuracy of process time.

The greatest challenge in utilizing the model is the issue of updating when process changes occur. Nevertheless, knowledge of the frequency of which updated procedures or process changes occurs could be used to infer an appropriate updating frequency. 


\section{References}

1. Brunoe, T. D., \& Nielsen, P.: A Case of Cost Estimation in an Engineer-to-order Company Moving Towards Mass Customisation. International Journal of Mass Customisation, 4 (2012) 239-254

2. García-Crespo, Á, Ruiz-Mezcua, B., López-Cuadrado, J. L. et al.: A Review of Conventional and Knowledge Based Systems for Machining Price Quotation. J. Intell. Manuf., 1-19

3. H'mida, F., Martin, P., Vernadat, F.: Cost Estimation in Mechanical Production: The Cost Entity Approach Applied to Integrated Product Engineering. Int J Prod Econ, 103 (2006) 17-35

4. Jørgensen, K. A.: Information Modelling of Product Families. Unpublished, (2011)

5. Karlsson, C.: Researching operations management. Routledge (2009)

6. Koren, Y.: The global manufacturing revolution: Product-process-business integration and reconfigurable systems. John Wiley \& Sons (2010)

7. Koren, Y., \& Shpitalni, M.: Design of Reconfigurable Manufacturing Systems. Journal of Manufacturing Systems, 29 (2010) 130-141

8. Meier, H., \& Homuth, M.: Holistic Ramp-Up Management in SME-Networks. (2006) 123-128

9. Montgomery, D. C.: Introduction to statistical quality control. 5th edn. John Wiley \& Sons (2005)

10. Shtub, A., \& Versano, R.: Estimating the Cost of Steel Pipe Bending, a Comparison between Neural Networks and Regression Analysis. Int J Prod Econ, 62 (1999) 201-207

11. Surbier, L., Alpan, G., Blanco, E.: A Comparative Study on Production RampUp: State-of-the-Art and New Challenges. Production Planning \& Control, 25 (2014) 1264-1286

12. Verlinden, B., Duflou, J., Collin, P. et al.: Cost Estimation for Sheet Metal Parts using Multiple Regression and Artificial Neural Networks: A Case Study. Int J Prod Econ, 111 (2008) 484-492

13. Westkämper, E., \& Westkaemper, E.: Research for Adaptive Assembly. (2006) $15-17$

14. Wiendahl, H., ElMaraghy, H. A., Nyhuis, P. et al.: Changeable ManufacturingClassification, Design and Operation. CIRP Annals-Manufacturing Technology, 56 (2007) 783-809 